\title{
A retail audit of mosquito control products in Busia County, western Kenya
}

\author{
Prisca A. Oria', Vincent Moshi ${ }^{1}$, Julius I. Odero', Sheila Ekodir ${ }^{1}$, April Monroe², Steven A. Harvey³, \\ Eric Ochomo ${ }^{1}$ and Danielle Piccinini Black ${ }^{2^{*}}$ (1)
}

\begin{abstract}
Background: Approximately $70 \%$ of Kenya's population is at risk for malaria. The core vector control methods in Kenya are insecticide-treated mosquito nets (ITNs) and indoor residual spraying, with supplementary larval source management. In 2015, 21\% of ITNs were accessed through the private retail sector. Despite the private sector role in supplying mosquito control products (MCPs), there is little evidence on the availability, sales trends, and consumer preferences for MCPs other than ITNs. This study, a component of a larger research programme focused on evaluating a spatial repellent intervention class for mosquito-borne disease control, addressed this evidence gap on the role of the private sector in supplying MCPs.

Methods: A cross-sectional survey was deployed in a range of retail outlets in Busia County to characterize MCP availability, sales trends, and distribution channels. The questionnaire included 32 closed-ended and four open-ended questions with short answer responses. Descriptive analysis of frequency counts and percentages was carried out to glean insights about commercially available MCPs and the weighted average rank was used to determine consumer preferences for MCPs. Open-ended data was analysed thematically.
\end{abstract}

Results: Retail outlets that stocked MCPs commonly stocked mosquito coils (73.0\%), topical repellents (38.1\%), aerosol insecticide sprays (23.8\%) and ITNs (14.3\%). Overall, retailers reported the profits from selling MCPs were adequate and they overwhelmingly planned to continue stocking the products. Of respondents who stocked MCPs, 96.8\% responded that sales increased during long rains and 36.5\% that sales also surged during short rains. ITNs and babysize nets were often delivered by the wholesaler. Retailers of aerosol sprays, mosquito coils, and topical repellents either collected stock from the wholesaler or products were delivered to them. Other commercially available MCPs included insecticide incense sticks, electric mosquito strikers, insecticide soaps, electrically heated insecticide mats, and electric insecticide emanators, indicating a well-established market.

Conclusions: The wide range of MCPs in local retail outlets within the study area suggests the need and demand for mosquito control tools, in addition to ITNs, that are affordable, easy to use and effective. The presence of a wide range of MCPs, is a promising sign for the introduction of a spatial repellent intervention class of products that meets consumer needs and preferences.

Keywords: Malaria, Spatial repellent, Mosquito control, Retail audit, Retail outlets, Insecticide-treated mosquito nets, Aerosol sprays, Mosquito coils, Topical repellents, Kenya

*Correspondence: danielle.piccinini@jhu.edu

2 Johns Hopkins Center for Communication Programs, Baltimore, MD, USA

Full list of author information is available at the end of the article

\section{Background}

Despite global efforts to reduce malaria prevalence and incidence, malaria remains a major global health concern. In 2019, an estimated 229 million cases and 409,000 
malaria deaths occurred worldwide with $94 \%$ of cases and deaths occurring in sub-Saharan Africa [1]. In Kenya, approximately $70 \%$ of the population is at risk for malaria and according to the 2015 Kenya Malaria Indicator Survey (KMIS), prevalence in the western lake endemic region was 27\% [2]. Approximately 3 million malaria cases occurred in Kenya in 2019 [1].

Vector control is a key malaria prevention intervention and is one of the primary malaria prevention measures in Kenya. According to the Kenya National Malaria Strategy 2019-2023, the core vector control methods are insecticide-treated mosquito nets (ITNs) and indoor residual spraying (IRS), with supplementary larval source management implemented on a small scale. IRS was first implemented in Kenya from 2008 to 2012 using pyrethroids, but was not implemented from 2013 to 2016 following widespread vector resistance to pyrethroids [3]. Following the registration of an organophosphate insecticide in 2016, IRS resumed and was last deployed in 2019 in Homabay and Migori counties. Larviciding has been implemented in a few research-based small-scale trials in western Kenya [4, 5].

The Division for National Malaria Programme distributes ITNs through mass campaigns every three years in malaria endemic and epidemic-prone areas to achieve universal coverage (one net per two people) [3]. Other channels of ITN distribution include antenatal care and child welfare clinics for pregnant women and young children, social marketing at designated locations, and retail sale through commercial outlets [2]. While these distribution channels have broadened coverage, achieving and maintaining universal coverage remains a challenge due the inaccessibility of ITNs for the at-risk population in its entirety and loss of physical integrity of ITNs over time $[6,7]$. In addition to the community directed mosquito control efforts organized by the government with proven efficacious interventions, there exists a considerable market for other mosquito control products (MCPs) including but not limited to mosquito coils, aerosol sprays, and topical repellents. This market demand exists even though evidence of malaria prevention efficacy of these products is lacking.

Retail markets are key malaria control product suppliers in many developing countries [8-10], and retail audits help estimate market trends. Audits collect data on sales trends, stock, supply chains, and competition. In malaria research, audits have focused primarily on medicines and ITNs [9-14], ignoring other MCPs like mosquito coils, aerosol sprays, and topical repellents. Despite free distribution efforts, supermarkets and other private shops supply $21 \%$ of Kenya's ITNs, [2] demonstrating the retail sector's importance for net acquisition. However, except for nets, minimal data is available on MCPs in retail outlets. Kenya's only two previous studies examining the role of shops in mosquito control found that many households employ multiple MCPs $[12,15]$, often including coils and sprays in addition to ITNs.

This retail audit was a precursor to a larger research programme known as AEGIS or Advancing Evidence for the Global Implementation of Spatial Repellents. AEGIS will conduct a clinical trial to test the efficacy of a newly developed spatial repellent-Mosquito Shield ${ }^{\mathrm{TM}}-$ for malaria control. Details of that trial (clinical trial registration pending) will be provided elsewhere. Mosquito Shield $^{\mathrm{TM}}$ consists of a plastic sheet infused with a longlasting formulation of transfluthrin, a World Health Organization (WHO) approved insecticide. It is intended as a supplement to, not a replacement for, ITNs. Once installed, Mosquito Shield ${ }^{\mathrm{TM}}$ releases microscopic transfluthrin particles into the air over a fixed period of time to repel or kill mosquitoes. While Mosquito Shield ${ }^{\mathrm{TM}}$ is not currently envisioned as a retail product, use of other MCPs available on the retail market could affect its acceptance among end-users. Thus, this retail audit aimed to understand the current local mosquito control landscape from a market angle through a descriptive cross-sectional survey.

\section{Methods}

\section{Study site and population}

This study was carried out in Teso South and Teso North sub-counties $\left(0^{\circ} 36^{\prime} 25.2^{\prime \prime} \mathrm{N}, 34^{\circ} 16^{\prime} 33.6^{\prime \prime} \mathrm{E}\right)$ which cover $559 \mathrm{~km}^{2}$ of Busia County in western Kenya $[16,17]$. The average altitude of the area is $1208 \mathrm{~m}$ above sea level [18]. The mean annual rainfall ranges between 800 and 1700 $\mathrm{mm}$ in most parts of the sub-counties, while other parts receive up to $2000 \mathrm{~mm}$ [16]. Temperatures are homogenous with an annual mean maximum between 26 and $30{ }^{\circ} \mathrm{C}$ and mean minimum between 14 and $22^{\circ} \mathrm{C}$ [19].

The population of the area is predominantly of the Iteso ethnic group. The population at risk for malaria in the two sub-counties is the combined total population of approximately 306,150 people, according to the 2019 Kenya Population and Housing Census. Subsistence farming and small-scale trade are the dominant economic activities carried out by the inhabitants. The area is part of the lake endemic region, which has intense malaria transmission throughout the year, with peaks during the long and short rainy seasons, which generally occur in May to July and October to December [2]. ITNs have, and continue to be, distributed freely there with the aim of universal coverage, and as such, are the main interventions used by residents against malaria vectors. 


\section{Study procedures}

To develop a sampling frame, field workers conducted a census of all retail outlets in the study area using GPSenabled tablets. Names and telephone numbers of each outlet's attendant or owner were also noted along with whether the outlet currently stocked or had previously stocked MCPs. Outlets were categorized as either $d u k a$ (small retail shop), pharmacy, agrovet (supply store for agricultural and veterinary products), supermarket, market stall, hawker (mobile seller) or other.

To ensure a sample representative of all retail outlets in the study area, the study used stratified random sampling based on the census. Quotas were set for different outlet types and whether the outlet currently stocked or reported previously stocking MCPs. Outlets observed to have MCPs on the day of the census were categorized as "currently stocking." If no MCPs were present on the day of the census, the enumerator asked the shop attendant or owner whether they had stocked MCPs at some point in the past. Those who responded "yes" were categorized as "previously stocked," while those who responded "no" were categorized as "never stocked" (Fig. 1). Initially the study team intended to sample 50 retail outlets in each category yielding a total sample of 250 . However, the census revealed that duka currently stocking MCPs and $d u k a$ that had previously stocked MCPs were the only categories with more than 50 outlets. Thus, a random sample of 50 outlets was selected from each of the two

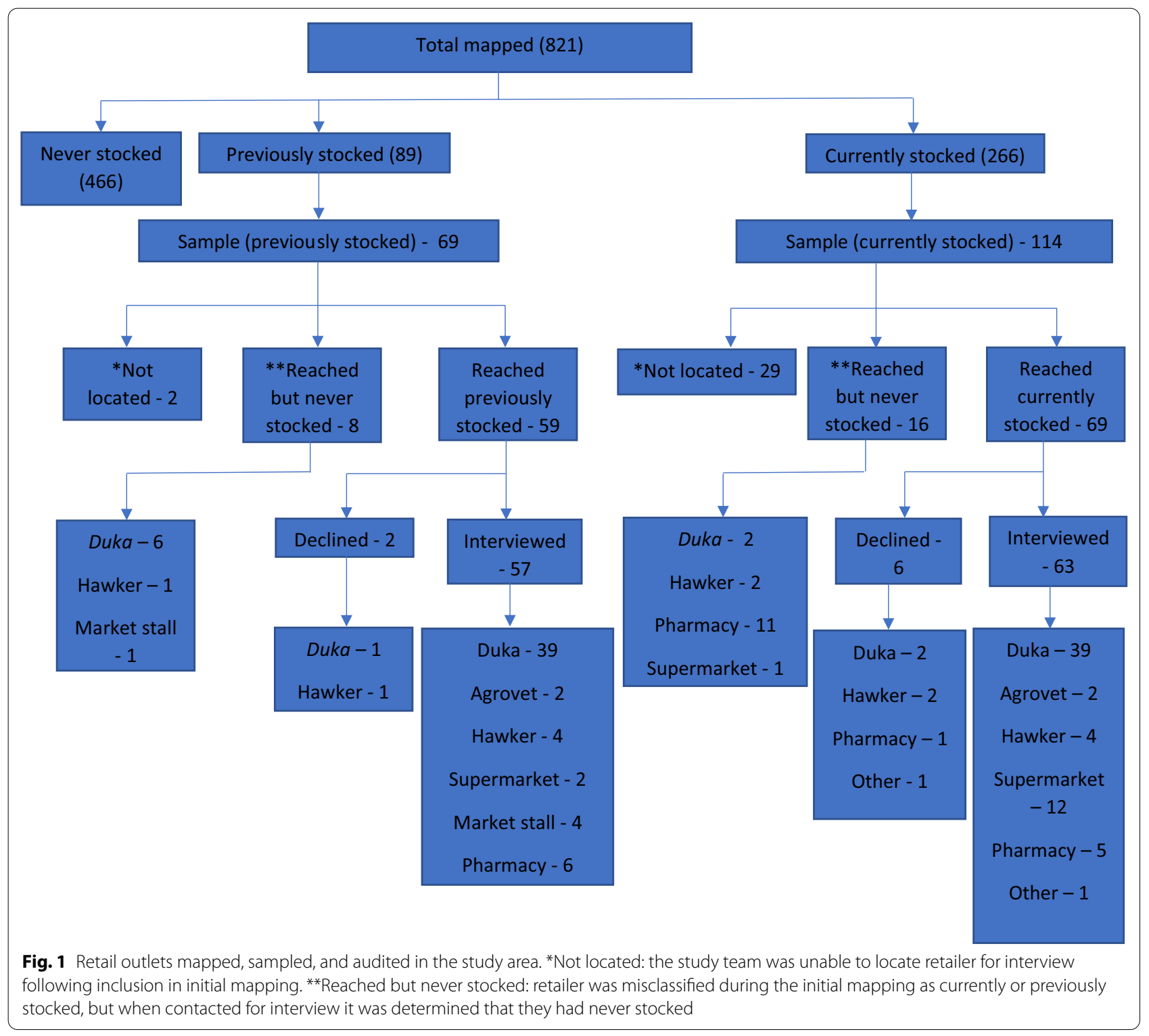


duka categories using a random number generator. For other categories, the study team attempted to include all outlets in each category.

\section{Data collection}

A structured tablet-based questionnaire was used to facilitate audit interviews. The questionnaire included 32 closed-ended questions and four open-ended short answer questions. Questions covered information on the role of the person interviewed, types of MCPs sold, sales trends, seasonal variations in sales, stock levels, supply chains, pricing structure, profit margins, factors affecting demand, and customer preferences as perceived by the interviewee in each outlet. The questionnaire was available in English, Kiswahili, and Ateso. Respondents selected their preferred language. The questionnaire was pre-tested in six retail outlets not included in the study before a final version was developed.

Fieldworkers fluent in the local language and with social science research training and experience collected data. The fieldworkers were trained on the content of the questionnaire, consenting procedures, research ethics and collection and transfer of data using the tablet before beginning fieldwork. Only participants 18 years and older who were either owners, managers or attendants of the retail outlet were interviewed.

During the interview process, interviewers requested to see and photograph MCPs stocked in the retail outlet. This form of observation provided triangulation for the information reported by the participant. The term ITN was used for nets treated with insecticides, UTNs for those without indications of insecticide treatment, and bed nets for a potential mix of insecticide-treated and untreated nets.

\section{Data analysis}

Interview data was captured using CommCare 2.47.4 (Dimagi, Inc., Cambridge, MA, USA) and later downloaded into Microsoft Excel 2003 (Microsoft, Washington, USA) using CSV file format. The quantitative data was cleaned, validated, and translated into English if originally collected in Kiswahili or Ateso. The cleaned data was transferred to STATA 13 (StataCorp, College Station, Texas, USA) where descriptive analysis of frequency counts and percentages was conducted. Weighted average rank $\frac{\sum_{r} n_{r} * r}{\sum_{r} n_{r}}$ was used to determine customer preferences of MCPs based on participants' knowledge of their own sales and those of other retail outlets.

Translated short answer data was transferred to Microsoft Word where two team members independently created codes by hand based on the questionnaire and data. They discussed the differences in their codebooks and then reconciled them into a single codebook. The codebook included reasons for surges and dips in sales, reasons retailers stopped selling, and factors that affected the demand for MCPs. Two other team members coded the interview data. A team member collated data relevant to each code, collated codes into themes and drafted the report.

\section{Results}

Retail outlets in the study area

A total of 821 retail outlets were identified and mapped in the study area census. This included 266 that reported currently stocking MCPs, 89 that reported previously stocking MCPs, and 466 that reported never having stocked MCPs (Fig. 1). Dukas (66.38\%) constituted the largest number of retail outlets, while agrovets (2.19\%) were the fewest. Other outlets included: hawkers (10.72\%), market stalls (8.77\%), pharmacy (5.60\%), supermarkets (2.31\%), and others such as wholesalers, hair salons, and barber shops (4.02\%).

Of the 89 outlets reported in the census as previous MCP vendors, 69 were sampled through a combination of random sampling of dukas plus inclusion of all representatives of other outlet types. Field workers were unable to locate 2 of these and 8 , when visited for the audit, said they had never stocked MCPs. Of the remaining 59, 2 declined to participate in the audit leaving a final sample of 57 former MCP vendors. Of the 266 identified as current MCP vendors during the census, 114 were sampled through a combination of random sampling of dukas plus inclusion of all representatives of other outlet types. Field workers were unable to locate 29 of these and 16, when visited for the audit, said they had never stocked. Of the remaining 69 outlets, 6 declined to participate in the audit leaving a final sample of 63 current MCP vendors. Thus, the overall sample audited included 57 former MCP vendors and 63 current vendors, for a total sample of 120 .

\section{Characteristics of retail outlets where interviews were conducted}

Most (78.9\%) interview participants were retail outlet owners; others were store managers (14.3\%) and store attendants (6.8\%). Interviews were conducted in 120 retail outlets, 78 (65\%) of which were dukas, as shown in Table 1.

\section{MCPs stocked in retail outlets currently and previously stocking}

As shown in Table 2, retail outlets that currently stocked MCPs commonly stocked mosquito coils (73.0\%), topical repellents (38.1\%), aerosol insecticide sprays (23.8\%) and ITNs (14.3\%). Outlets that previously stocked MCPs had 
Table 1 Characteristics of retail outlets identified in census $(n=821)$ and interviewed $(n=120)$

\begin{tabular}{|c|c|c|c|c|c|c|}
\hline \multirow[t]{2}{*}{ 1. Type of outlet } & $\begin{array}{l}\text { 2. Total outlets } \\
\text { identified in study } \\
\text { area }\end{array}$ & $\begin{array}{l}\text { 3. Study area outlets } \\
\text { that currently stocked } \\
\text { MCPs }\end{array}$ & $\begin{array}{l}\text { 4. Interviewed outlets } \\
\text { that currently stocked } \\
\text { MCPs }\end{array}$ & $\begin{array}{l}\text { 5. Study area outlets } \\
\text { that reported } \\
\text { previously stocking } \\
\text { MCPs }\end{array}$ & $\begin{array}{l}\text { 6. Interviewed } \\
\text { outlets that reported } \\
\text { previously stocking } \\
\text { MCPs }\end{array}$ & $\begin{array}{l}\text { 7. Total } \\
\text { interviewed } \\
(4+6)\end{array}$ \\
\hline & $\mathrm{n}$ & n (\%) & n (\%) & n (\%) & n (\%) & n (\%) \\
\hline Duka & 545 & $202(37.1)$ & $39(19.3)$ & $70(12.8)$ & $39(55.7)$ & $78(14.3)$ \\
\hline Supermarket & 19 & $13(68.4)$ & $12(92.3)$ & $3(15.8)$ & $2(66.7)$ & $14(73.7)$ \\
\hline Pharmacy & 46 & $27(58.7)$ & $5(18.5)$ & $2(4.4)^{b}$ & $6^{b}$ & $11(23.9)$ \\
\hline Hawker & 88 & $15(17.1)$ & $4(26.7)$ & $7(8.0)$ & $4(57.1)$ & $8(9.1)$ \\
\hline Market stall & 72 & $3(4.2)$ & $0(0.0)$ & $5(6.9)$ & $4(80.0)$ & $4(5.6)$ \\
\hline Agrovet & 18 & $4(22.2)$ & $2(50.0)$ & $1(5.6)^{b}$ & $2^{b}$ & $4(22.2)$ \\
\hline Other $^{\mathrm{a}}$ & 33 & $2(6.1)$ & $1(50.0)$ & $1(3.0)$ & $0(0.0)$ & $1(3.0)$ \\
\hline Total & 821 & $266(32.4)$ & 63 (23.7) & 89 (10.8) & 57 (64.0) & $120(14.6)$ \\
\hline
\end{tabular}

a Wholesaler, boutique, electronic shop, hotel, kiosk, salon, shoe store, tailor store, utensils store, welding store, barber shop, movie hall, mobile telephone handset shop

b Numbers interviewed are greater than numbers mapped for pharmacy and agrovet due to misclassification of outlets during initial mapping as currently or previously stocked

Table 2 Mosquito control products stocked in retail outlets in interview sample $(n=120)$

\begin{tabular}{|c|c|c|c|c|c|c|c|}
\hline \multirow[t]{2}{*}{ Retail outlet type } & \multirow[t]{2}{*}{ Stocking status } & \multirow{2}{*}{$\begin{array}{l}\text { Insecticide- } \\
\text { treated nets } \\
\mathrm{n}(\%)\end{array}$} & \multirow{2}{*}{$\begin{array}{l}\text { Baby nets } \\
\text { n (\%) }\end{array}$} & \multirow{2}{*}{$\begin{array}{l}\text { Aerosol } \\
\text { insecticide } \\
\text { sprays } \\
\mathrm{n}(\%)\end{array}$} & \multirow{2}{*}{$\begin{array}{l}\text { Mosquito coils } \\
\text { n (\%) }\end{array}$} & \multirow{2}{*}{$\begin{array}{l}\text { Topical repellents } \\
\text { n (\%) }\end{array}$} & \multirow{2}{*}{$\begin{array}{l}\text { Other }^{b} \\
n(\%)\end{array}$} \\
\hline & & & & & & & \\
\hline \multirow[t]{2}{*}{ Duka } & Currently $n=39$ & $4(10.3)$ & 0 & $4(10.3)$ & 33 (84.6) & $12(30.8)$ & $15(38.5)$ \\
\hline & Previously $n=39$ & $9(23.1)$ & 0 & $2(5.1)$ & $34(87.2)$ & $8(20.5)$ & $2(5.1)$ \\
\hline \multirow[t]{2}{*}{ Pharmacy } & Currently $n=5$ & 0 & 0 & 0 & 0 & $3(0.6)$ & $4(0.8)$ \\
\hline & Previously $n=6$ & $3(50.0)$ & 0 & $2(33.3)$ & $2(33.3)$ & $3(50.0)$ & $1(16.7)$ \\
\hline \multirow[t]{2}{*}{ Supermarket } & Currently $n=12$ & $5(41.7)$ & $3(25.0)$ & $9(75.0)$ & $11(91.7)$ & $6(50.0)$ & $11(91.7)$ \\
\hline & Previously $n=2$ & 0 & 0 & 0 & $2(100.0)$ & $1(50.0)$ & $1(50.0)$ \\
\hline \multirow[t]{2}{*}{ Hawker } & Currently $n=4$ & 0 & 0 & $1(25.0)$ & $2(50.0)$ & $2(50.0)$ & 0 \\
\hline & Previously $n=4$ & $2(50.0)$ & 0 & 0 & $3(75.0)$ & $1(25.0)$ & 0 \\
\hline \multirow[t]{2}{*}{ Market stall } & Currently $n=0$ & 0 & 0 & 0 & 0 & 0 & 0 \\
\hline & Previously $n=7$ & $3(42.9)$ & 0 & $1(14.3)$ & $1(14.3)$ & $2(28.6)$ & 0 \\
\hline \multirow[t]{2}{*}{ Agrovet } & Currently $n=2$ & 0 & 0 & $1(50.0)$ & 0 & 0 & $1(50.0)$ \\
\hline & Previously $n=2$ & 0 & 0 & 0 & 0 & 0 & $2(100.0)$ \\
\hline \multirow[t]{2}{*}{ Other $^{a}$} & Currently $n=1$ & 0 & 0 & 0 & 0 & $1(100.0)$ & 0 \\
\hline & Previously $n=0$ & 0 & 0 & 0 & 0 & 0 & 0 \\
\hline \multirow[t]{2}{*}{ Total } & Currently $n=63$ & $9(14.3)$ & $3(4.8)$ & 15 (23.8) & $46(73.0)$ & $24(38.1)$ & $31(49.2)$ \\
\hline & Previously $n=57$ & $17(29.8)$ & 0 & $5(8.8)$ & $42(73.7)$ & $15(26.3)$ & $6(10.5)$ \\
\hline
\end{tabular}

a Wholesaler

b Untreated bed nets, residual insecticide sprays, electric mosquito strikers, malaria prophylaxis, insecticide incense sticks, insecticide soap, electric mosquito mats, electric mosquito repellent, insect killer, mosquito repellents and insecticide candles

frequently stocked mosquito coils (73.7\%), ITNs (29.8\%), and topical repellents $(26.3 \%)$.

\section{Product supply chain and frequency of restocking in retail outlets that currently stocked MCPs}

ITNs and baby-size nets were mainly restocked monthly or depending on sales and were most often delivered to the retail outlet by the wholesaler with upfront cash payment, as shown in Table 3. Retailers of aerosol sprays, mosquito coils, and topical repellents often paid cash upfront to the wholesaler for stock, which they either picked up from the wholesaler or products were delivered to them. 
Table 3 Frequency, mode, source and payment method for retail outlets that currently stocked mosquito control products ( $\mathrm{n}=63$ )

\begin{tabular}{|c|c|c|c|c|c|c|c|}
\hline \multirow[t]{2}{*}{ Stocking and supply chain } & \multirow[t]{2}{*}{ Mosquito control product } & \multirow{2}{*}{$\begin{array}{l}\text { ITN } \\
\mathrm{n}=9 \\
\mathrm{n}(\%)\end{array}$} & \multirow{2}{*}{$\begin{array}{l}\text { Baby-sized bed net } \\
n=3 \\
n(\%)\end{array}$} & \multirow{2}{*}{$\begin{array}{l}\text { Aerosol } \\
\text { insecticide } \\
\text { sprays } \\
\mathrm{n}=16 \\
\mathrm{n}(\%)\end{array}$} & \multirow{2}{*}{$\begin{array}{l}\text { Mosquito coils } \\
n=45 \\
n(\%)\end{array}$} & \multirow{2}{*}{$\begin{array}{l}\text { Topical repellents } \\
n=24 \\
n(\%)\end{array}$} & \multirow{2}{*}{$\begin{array}{l}\text { Other } \\
\mathrm{n}=19 \\
\mathrm{n}(\%)\end{array}$} \\
\hline & & & & & & & \\
\hline \multirow[t]{6}{*}{ Frequency of stocking } & Weekly & 0 & 0 & $2(12.5)$ & $7(15.6)$ & $3(12.5)$ & $3(15.8)$ \\
\hline & 2 weeks & 0 & 0 & $2(12.5)$ & $7(15.6)$ & 0 & $2(10.5)$ \\
\hline & Monthly & $5(55.6)$ & $2(66.7)$ & $6(37.5)$ & $12(26.7)$ & $11(45.8)$ & $3(15.8)$ \\
\hline & > Monthly & $2(22.2)$ & 0 & $3(18.8)$ & $5(11.1)$ & $3(12.5)$ & $1(5.3)$ \\
\hline & Depends on sales & $2(22.2)$ & $1(33.3)$ & $3(18.8)$ & $13(28.9)$ & $4(16.7)$ & $5(26.3)$ \\
\hline & Other ${ }^{\mathrm{a}}$ & 0 & 0 & 0 & $1(2.2)$ & $3(12.5)$ & $5(26.3)$ \\
\hline \multirow[t]{2}{*}{ How stock was obtained } & Delivered & $6(66.7)$ & $3(100.0)$ & $14(87.5)$ & $22(48.9)$ & $11(45.8)$ & $17(89.5)$ \\
\hline & Pickup & $3(33.3)$ & 0 & $2(12.5)$ & $23(51.1)$ & $13(54.2)$ & $2(10.5)$ \\
\hline \multirow[t]{2}{*}{ Where stock was obtained } & Wholesaler & $9(100.0)$ & $2(66.7)$ & $15(93.8)$ & $43(95.6)$ & $24(100.0)$ & $18(94.7)$ \\
\hline & Other ${ }^{b}$ & 0 & $1(33.3)$ & $1(6.2)$ & $2(4.4)$ & 0 & $1(5.3)$ \\
\hline \multirow[t]{2}{*}{ How Retailers Paid for stock } & On consignment & $2(22.2)$ & $1(33.3)$ & $5(31.2)$ & $5(11.1)$ & $2(8.3)$ & $3(15.8)$ \\
\hline & Full Value & $7(77.8)$ & $2(66.7)$ & $11(68.8)$ & 40 (88.9) & $22(91.7)$ & $16(84.2)$ \\
\hline
\end{tabular}

${ }^{a}$ Customer request, depends on season, depends on supplier, don't know and first stock

b Pharmacy, retailer, distributor, don't know

c Untreated bed nets, electric mosquito mat, electric mosquito repellent, malaria prophylaxis, insect killer, mosquito repellents, mosquito candles, soap, insecticide incense sticks, electric mosquito striker, residual insecticide spray

\section{Profit adequacy and plans to continue stocking MCPs}

Overall, retailers that currently stocked MCPs reported the profits were adequate and they overwhelmingly planned to continue stocking the products, as shown in Table 4. Of retailers who stocked ITNs, $55.6 \%$ (5 out of 9) reported that the profit was adequate. All respondents stocking ITNs, UTNs, baby-sized nets, aerosol insecticide sprays, and residual insecticide spray planned to continue stocking the products. Of those stocking mosquito coils and topical repellents, $97.8 \%$ (44 out of 45) and 91.7\% (22 out of 24), respectively, planned to continue stocking the products. A couple (2 out of 24) retailers of topical repellents planned to stop stocking the products.

\section{Ranking of stocked MCPs when more than one product was stocked}

Based on retailers' own MCP sales and their knowledge of other retail outlets' sales, study participants ranked mosquito coils, topical repellents, aerosol insecticide sprays and ITNs as the products most frequently purchased by customers in outlets that stocked more than one MCP, as shown in Table 5.

Table 4 Profit margins, adequacy and plans to keep stocking products $(n=63)$

\begin{tabular}{|c|c|c|c|c|c|c|c|}
\hline \multirow[t]{3}{*}{ Mosquito control product } & \multirow{3}{*}{$\begin{array}{l}\begin{array}{l}\text { Profit margin } \\
\text { (Kenya Shillings) }\end{array} \\
\text { (min, max) }\end{array}$} & \multicolumn{3}{|c|}{ Perception of profit } & \multicolumn{3}{|c|}{ Keep selling } \\
\hline & & \multirow{2}{*}{$\begin{array}{l}\text { Adequate } \\
\text { n (\%) }\end{array}$} & \multirow{2}{*}{$\begin{array}{l}\text { Inadequate } \\
\mathrm{n}(\%)\end{array}$} & \multirow{2}{*}{$\begin{array}{l}\text { Other }{ }^{\mathrm{a}} \\
\mathrm{n}(\%)\end{array}$} & \multirow{2}{*}{$\begin{array}{l}\text { Yes } \\
\text { n (\%) }\end{array}$} & \multirow{2}{*}{$\begin{array}{l}\text { No } \\
\text { n (\%) }\end{array}$} & \multirow{2}{*}{$\begin{array}{l}\text { Don't know } \\
\text { n (\%) }\end{array}$} \\
\hline & & & & & & & \\
\hline ITN $(n=9)$ & $(50,200)$ & $5(55.6)$ & $4(44.4)$ & 0 & $9(100.0)$ & 0 & 0 \\
\hline UTN $(n=1)$ & $(50,50)$ & $1(100.0)$ & 0 & 0 & $1(100.0)$ & 0 & 0 \\
\hline Baby-sized bed net $(n=3)$ & $(50,50)$ & $1(33.3)$ & $1(33.3)$ & $1(33.3)$ & $3(100.0)$ & 0 & 0 \\
\hline Aerosol insecticide sprays $(n=16)$ & $(20,265)$ & $11(68.8)$ & $5(31.2)$ & 0 & $16(100.0)$ & 0 & 0 \\
\hline Mosquito coils $(n=45)$ & $(0.5,165.5)$ & $30(66.7)$ & $14(31.1)$ & $1(2.2)$ & $44(97.8)$ & 0 & $1(2.2)$ \\
\hline Topical repellents $(n=24)$ & $(5,48)$ & $15(62.5)$ & $8(33.3)$ & $1(4.2)$ & $22(91.7)$ & $2(8.3)$ & 0 \\
\hline Other $^{b}(n=18)$ & $(3,150)$ & $13(72.2)$ & $5(27.8)$ & 0 & $15(83.3)$ & $2(11.1)$ & $1(5.6)$ \\
\hline
\end{tabular}

a Neither adequate nor inadequate

b Electric mosquito mat, electric mosquito repellent, insect killer, malaria prophylaxis, mosquito repellents, mosquito candles, soap, insecticide incense sticks, electric mosquito striker, and residual insecticide spray 
Table 5 Ranking of most frequently sold mosquito control products when more than one product was stocked

\begin{tabular}{|c|c|c|c|c|c|c|c|}
\hline \multirow[t]{2}{*}{ Mosquito control product } & $\begin{array}{l}\text { 1st (most commonly } \\
\text { sold) }\end{array}$ & 2nd & $3 r d$ & 4th & 5 th & $\begin{array}{l}\text { 6th (least commonly } \\
\text { sold) }\end{array}$ & $\begin{array}{l}\text { By } \\
\text { weighted } \\
\text { rank }\end{array}$ \\
\hline & $n$ & $n$ & $\mathrm{n}$ & $n$ & $n$ & $\mathrm{n}$ & $\mathrm{n}$ \\
\hline ITN $(n=8)$ & 3 & 1 & 4 & - & - & - & 3 \\
\hline Baby-sized bed net $(n=3)$ & - & - & - & 1 & 1 & 1 & 6 \\
\hline Aerosol insecticide sprays $(n=13)$ & 6 & 4 & 2 & 1 & - & - & 2 \\
\hline Mosquito Coils $(n=23)$ & 15 & 8 & - & - & - & - & 1 \\
\hline Topical Repellents $(n=19)$ & 2 & 10 & 3 & 3 & 1 & - & 4 \\
\hline Other $^{a}(n=14)$ & 1 & 4 & 4 & 2 & 2 & 1 & 5 \\
\hline
\end{tabular}

${ }^{a}$ UTN, electric mosquito mat, electric mosquito repellent, insect killer, mosquito repellents, mosquito candles, soap, insecticide incense sticks, electric mosquito striker, and residual insecticide spray

When the ranking by retailers was weighted, mosquito coils, aerosol insecticide sprays, ITNs, and topical repellents were perceived by retailers as the products most frequently purchased by consumers in that order.

\section{Additional MCPs used by residents and their sources based on retailer reports}

In addition to the MCPs they sold, retailers also reported that consumers used products obtained elsewhere. These products included ITNs (49), aerosol sprays (16), topical repellents (14) and mosquito coils (11), among other products, as shown in Table 6.

The highest proportion (65.3\%) of ITNs were reportedly obtained from antenatal and immunization clinics, $59.2 \%$ from free mass distribution and another 59.2\% purchased from retail outlets. Mosquito coils were reportedly exclusively purchased from retail outlets. Topical repellents were mainly (92.9\%) obtained from retail outlets as were aerosol sprays (93.8\%). A type of product could reportedly be obtained from different sources, i.e., because bed nets can be obtained from mass distribution and retail outlets the percentages add up to more than 100.

\section{Seasonal variation in sales of MCPs}

Of respondents who currently stocked MCPs, 96.8\% (61 of 63) responded that sales surged during long rains and $36.5 \%$ (23 of 63) informed sales also surged during short rains. Fifty-seven $(98.3 \%)$ respondents reported a dip in sales of MCPs during the dry season.

\section{Reasons for surges and dips in sales of MCPs}

The main reason mentioned for increased sales of MCPs was an increase in mosquito numbers mainly a result of an increase in breeding grounds from stagnant rainwater. Other reasons for increased mosquito

Table 6 Additional mosquito control products used by residents and their sources based on retailer reports $(n=63)$

\begin{tabular}{|c|c|c|c|c|c|c|c|}
\hline \multirow[t]{3}{*}{ Product } & \multirow{3}{*}{$\begin{array}{l}\text { Frequency } \\
\mathrm{n}\end{array}$} & \multicolumn{6}{|c|}{ Where product was obtained } \\
\hline & & \multirow{2}{*}{$\begin{array}{l}\text { Free distributions } \\
\text { - }(\%)\end{array}$} & \multirow{2}{*}{$\begin{array}{l}\text { Hospital/health } \\
\text { centres } \\
\text { n (\%) }\end{array}$} & \multirow{2}{*}{$\begin{array}{l}\text { Retail shop } \\
\text { n (\%) }\end{array}$} & \multirow{2}{*}{$\begin{array}{l}\text { Homemade } \\
\mathrm{n}(\%)\end{array}$} & \multirow{2}{*}{$\begin{array}{l}\text { Supermarket } \\
\mathrm{n}(\%)\end{array}$} & \multirow{2}{*}{$\begin{array}{l}\text { Other }^{\mathrm{a}} \\
\mathrm{n}(\%)\end{array}$} \\
\hline & & & & & & & \\
\hline Aerosol sprays & 16 & $1(6.3)$ & - & $15(93.8)$ & - & $4(25.0)$ & $1(6.3)$ \\
\hline Bed nets & 49 & $29(59.2)$ & $32(65.3)$ & $29(59.2)$ & - & $2(4.1)$ & $1(2.0)$ \\
\hline Electric emanator & 3 & - & - & $2(66.7)$ & - & $2(66.67)$ & 0 \\
\hline Electric mosquito striker & 8 & $1(12.5)$ & - & 7 (87.5.) & - & & $1(12.5)$ \\
\hline Leaves/smoke & 8 & - & - & & $7(85.7)$ & & $1(12.5)$ \\
\hline Mosquito coils & 11 & - & - & $11(100.0)$ & - & & \\
\hline Topical repellents & 14 & - & - & $13(92.9)$ & - & $2(14.3)$ & $2(14.3)$ \\
\hline Other $^{b}$ & 6 & - & - & $5(83.3)$ & - & 1 (16.7) & - \\
\hline
\end{tabular}

A type of product could reportedly be obtained from different sources, i.e., because bed nets can be obtained from mass distribution and retail outlets the percentages add up to more than 100

a Pharmacy, hawkers, wholesaler, and home-made

b Indoor residual spray, insecticide incense sticks, soap, celling fan, blust bulb 
numbers included: longer grass, presence of swamps and increase in mosquito breeding. Student purchases for overnight field trips, increased awareness of mosquito control and increased household population, also led to a surge in sales.

The main reasons mentioned for decreased sales of MCPs was a reduction in number of mosquitoes or absence of mosquitoes. Both a reduction and absence of mosquitoes were mainly attributed to increased heat or sunny weather, fewer/lack of breeding grounds as stagnant rainwater dried up and reduction in bushes as crops were harvested. Other reasons for a reduction in sales of MCPs were free distribution of ITNs, few malaria cases, and absence of mosquitoes due to dry weather conditions. Decrease in malaria was associated with fewer or no mosquitoes in houses.

\section{Factors that affected the demand for MCPs based on retailer reports}

\section{Factors reported to affect the demand for MCPs}

When asked what factors influenced demand for MCPs, retailers mentioned price most frequently (45.6\%), followed closely by season/weather (43.5\%). These results are presented in Fig. 2. A considerable number of retailers had different responses (43.5\%), apart from what were provided as likely choices, which were collected qualitatively and are presented in the sections below.

\section{Factors reported to negatively affect the demand for MCPs}

The main factors that retailers reported to negatively affect demand for MCPs were adverse effects from product use, perceived ineffectiveness, inconvenience of use, short period of product use and inaccessibility. Adverse effects included bad smelling fumes, eye irritation, allergic reactions and coughs from burning mosquito coils; skin irritation from new ITNs; skin reactions and rashes from topical repellents; and the perception that ITNs introduced bed bugs in homes.

Retailers reported that generic products were perceived by consumers as inferior in quality to brand name products, which influenced demand for particular brands of products. Inconveniences for bed net use such as time needed to hang them and inability to carry them to funerals or overnight school field trips were perceived to have a negative effect on demand. The burden of topical repellents being easily wiped off by blankets and mosquito coils breaking easily and running out quickly were also perceived to negatively affect demand. Retailers also lacked products that were difficult to source or that suppliers had not delivered resulting to lost consumer interest. Other factors reported to negatively affect the demand for MCPs were lack of money to buy enough bed nets for the whole family and the need for electricity to power some MCPs.

\section{Factors reported to positively affect the demand for MCPs}

For MCPs generally, perceived effectiveness and trust in the product, increase in mosquitoes and malaria, and fear

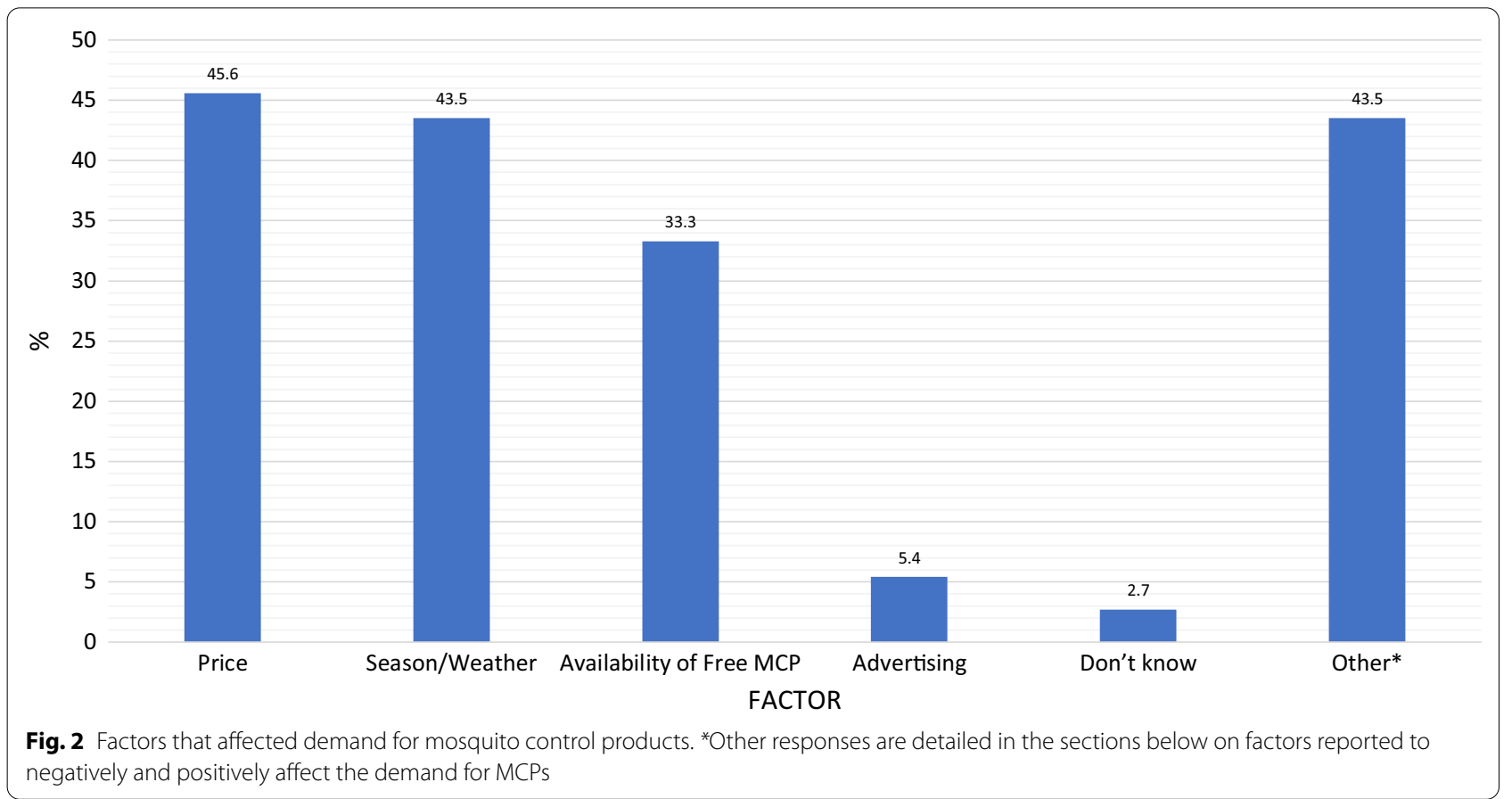


of mosquito bites were perceived as positively affecting demand. Customers specifically liked bed nets because they have a longer life of use.

\section{Retailer reasons for no longer stocking MCPs}

Low demand, customer complaints about adverse effects, and difficulties obtaining stock were the main reasons retailers did not stock MCPs when this study was conducted. Low demand was attributed to free distribution of ITNs in health facilities and people having ITNs. Retailers reported that customers often complained that burning coils emitted a bad smell and caused coughs and flu. Some customers did not like the smell of topical repellents. Sometimes shops had not restocked because either obtaining stock was difficult or their supplier had not delivered stock. Other reasons retailers had no stock included lack of money to restock and yet to restock soldout products.

Additional reasons retailers did not stock MCPs were customer complaints about perceived ineffectiveness, lack of capital, had stopped selling MCPs and had closed business.

\section{Discussion}

This study assessed the availability, supply chains, and sales trends of MCPs within the area selected for the AEGIS efficacy trial. While Mosquito Shield ${ }^{\mathrm{TM}}$, the spatial repellent to be assessed in the forthcoming clinical trial, is not currently intended for retail sale, the existing retail market for MCPs is likely to have an effect on consumer acceptance of Mosquito Shield ${ }^{\mathrm{TM}}$ and potential similar products. Knowing what MCPs retail outlets are currently selling is a first step towards understanding consumer preferences and how these preferences might affect uptake of a new product.

The audit found a wide range of MCPs on the market, mainly comprising mosquito coils, topical repellents, aerosol sprays, ITNs, and residual insecticide sprays. This widespread availability of MCPs is evidence that there is a market for such products in Busia County. While evidence shows that mosquito coils [20-23], topical repellents [24-26], and aerosol insecticide sprays [27] help reduce mosquito bites, there is no data to suggest these products reduce the incidence of clinical malaria [23, 28, 29]. Nevertheless, consumers are buying them.

In addition to these better-known MCPs, there were also insecticide incense sticks, electric mosquito strikers, insecticide soaps, electrically heated insecticide mats and electric insecticide emanators available, suggesting that the MCP market is well-enough established to support new, niche, products. While these data are cross-sectional and cannot be used to estimate market trends over time, the fact that new products are becoming available and retailers are stocking them provides some indication of market growth. The type of retailers surveyed operate on very small margins and typically cannot afford to stock products that do not sell. Therefore, the presence of these products in multiple retail outlets provides fairly strong evidence that consumers are purchasing them.

Mosquito coils, topical repellents, and aerosol insecticide sprays by design are easy to use and can provide protection against nuisance biting outside of sleeping hours. They fill a need that ITNs, which have high ownership in the study area [18] do not, thus suggesting that other MCPs still play an important role in mosquito control in this malaria endemic zone.

While ITNs provide protection indoors during sleeping hours, residents likely use additional personal protective measures for early evening indoor and outdoor mosquito biting. These findings mirror those of studies carried out elsewhere in Kenya that report household use of multiple MCPs, with sleeping under an ITN as the main method [12, 15]. In a study that assessed the role of shops in the treatment and control of childhood malaria along the coast of Kenya, $46.4 \%$ of the consumers reported using commercial pyrethrum mosquito coils, reinforcing the product's popularity [12]. This may be related to the affordability, perceived effectiveness, and convenience of using mosquito coils to protect against early evening biting when ITNs cannot be deployed or are unavailable. According to retailers in this study, price had the most impact on demand for MCPs, closely followed by weather and free access. Rainy seasons were associated with increases in mosquito densities and may be a driving factor in seeking additional MCPs for use outside of sleeping hours. The study area is part of Kenya's malariaendemic lake region, but retailers perceived increases in mosquito abundance, malaria incidence and MCPs sales during rainy seasons. This is consistent with epidemiological evidence demonstrating that, while some malaria transmission occurs year-round, it peaks during the rainy seasons.

ITNs were hardly available in retail outlets despite retailers' belief that other retailers stocked them. This is likely the result of the easy ITN access: Kenya's National Malaria Control Programme distributes ITNs through mass campaigns every three years and routinely through antenatal care and child welfare clinics for pregnant women and young children [2]. Pharmacies, market stalls and hawkers reported previously selling ITNs but had stopped because of the low demand induced by free access. When asked which MCPs consumers used in addition to those sold in their own stores, $78 \%$ of retailers mentioned bed nets. Mosquito coils were widely available in dukas and supermarkets. While aerosol insecticide sprays and topical repellents were mainly found in 
dukas and supermarkets, hawkers and market stalls also stocked topical repellents.

Retailers obtain most of their MCP stock from wholesalers. Retailers of aerosol sprays, mosquito coils and topical repellents pay cash up front for stock, and products are either delivered to them or the retailer collects stock from the wholesaler. Difficulty obtaining supplies was one reason retailers often mentioned for having MCPs temporarily out of stock. Overall, however, retailers were satisfied with their profit margins from selling MCPs and planned to continue stocking them.

Regardless of whether a new spatial repellent intervention labelled for public health becomes available on the retail market, this audit makes clear that Busia County residents currently rely on retail outlets for MCPs that are complementary to ITNs now. It is essential to consider this fact when preparing to introduce such a spatial repellent into the malaria control portfolio, since currently available products could pose competition and inhibit uptake. It will be important to identify the consumer demand and preferences met by current MCPs (e.g., ease of use and use outside of sleeping hours), and position spatial repellents as a product that meets those needs more effectively and with fewer adverse effects. Another consideration for successful introduction of a novel spatial repellent is the potential power of branding. While this retail audit did not directly ask retailers about brands, a few brands for aerosol insecticide sprays, mosquito coils, and topical repellents featured repeatedly in our audit data indicating that they were top-of-mind.

\section{Limitations}

This study had a number of limitations. Probably the most important limitation of this study was the limited sample size, a result of the limited number of retail outlets in the study area. In this study, most of the retailers identified were dukas and there were insufficient numbers of other retailer categories to include 50 units of each. This issue was compounded by the fact that some itinerant retailers identified in the census could not be located again for an audit interview. Some identified in the census as current or previous MCP vendors reported never having sold MCPs when invited to participate in the audit. Retailers also showed some reluctance to reveal profit margins on MCPs fearing that such information might be shared with revenue and tax authorities or competitors. Additionally, because there are no current plans to distribute the new spatial repellent through retail channels, this study did not ask about retailers' potential willingness to stock it. Retailer willingness to stock the new spatial repellent, trends in pricing and the effect of pricing on product demand, and retailer perceptions of what would make the product more attractive to retail consumers, could be important questions for future research.

Since the objective of this study was to describe the retail landscape for MCPs in the study area, only retail vendors were interviewed. Thus, information about consumer preferences and purchasing patterns is based only on retailer reports. This means, for instance, that data is not available on whether certain classes of consumers prefer one category of retailer over another or what consumers do at any given time if their preferred retailer does not have their preferred product in stock. Likewise, the study does not provide direct information about wholesale markets or wholesale trends. Interviews with consumers and wholesalers to explore these questions would be appropriate for future research.

\section{Conclusions}

The presence and wide range of MCPs in local retail outlets suggest that there is a market for MCPs in Busia County. This indicates that there is ongoing demand for MCPs, in addition to freely distributed ITNs, that are affordable, easy to use, and effective in situations where ITNs cannot provide protection (i.e. outside of sleeping hours both indoors and outdoors). Mosquito coils, aerosol insecticide sprays and topical repellents were the most widely sold products, with mosquito coils being the dominant product likely because they met that criteria. Additionally, the new MCPs on the market; insecticide incense sticks, electric mosquito strikers, insecticide soaps, electrically heated insecticide mats, and electric insecticide emanators, are an indication that the market for MCPs is well-established.

This well-established market is a promising sign for the introduction of a spatial repellent product class that has proven efficacy for public health and meets consumer demand and preferences, such as ease of use and continuous protection indoors, outside of sleeping hours, without notable adverse effects. Mosquito coils were popular despite the need to frequently replenish and light them, irritating smell, and fumes that caused coughs. An odourless spatial repellent at an accessible price point, that requires infrequent replacement, could prove to be a popular product and potential supplement for coils.

\section{Abbreviations \\ AEGIS: Advancing Evidence for the Global Implementation of Spatial Repel- lents; GPS: Global Positioning System; IRS: Indoor residual spraying; ITN: Insecticide-treated mosquito net; KMIS: Kenya Malaria Indicator Survey; MCP: Mosquito control product; SR: Spatial repellent; UTN: Untreated bed net.}

\section{Acknowledgements}

We thank John P. Grieco (University of Notre Dame), the Principal Investigator of the AEGIS project, for his leadership and support. We also thank Nicole L. Achee (University of Notre Dame) for her constructive critique of the paper. We are grateful to Maurice Ombok and the mapping team for the GPS 
mapping of retail outlets, to Isaac Wamalwa for data collection, and to Jared Hendrickson (University of Notre Dame) for scripting the questionnaire into CommCare. We also thank interviewees for their time and effort in participating in the study.

\section{Authors' contributions}

$\mathrm{AM}, \mathrm{SAH}, \mathrm{EO}$, and DP were responsible for the study concept, study design, and drafting the research protocol and data collection instruments; $P A O, A M$ and DP trained the data collectors; PAO, JIO, and SE collected the data; PAO, $V M, J I O, S E$ and DP analysed the data; PAO drafted and managed edits to the manuscript; VM, JIO, SE, AM, SAH, EO and DP contributed to the manuscript; $\mathrm{AM}, \mathrm{SAH}, \mathrm{EO}$ and DP provided guidance and feedback throughout the study. All authors read and approved the final manuscript.

\section{Funding}

The project under which the data reported here was gathered, "Advancing Evidence for the Global Implementation of Spatial Repellents (AEGIS)," is made possible thanks to Unitaid funding and support (2018-29-UND). Unitaid finds new ways to prevent, treat and diagnose HIV/AIDS, tuberculosis and malaria more quickly, more cheaply and more effectively. It identifies innovative health solutions that show promise and invests in them to establish their viability so that partner organisations can then make them widely available. Unitaid addresses innovation barriers by supporting an integrated approach to health, accelerating the development and market introduction of better health products and by influencing the dynamics of the innovation landscape to benefit people in low resource settings. However, Unitaid had no role in the design of the study and collection, analysis, and interpretation of data and in the writing of the manuscript.

\section{Availability of data and materials}

The data sets generated and analysed during the current study are available from the corresponding author on reasonable request.

\section{Declarations}

\section{Ethics approval and consent to participate}

Ethical review and approval for this study was granted by the Johns Hopkins Institutional Review Board (IRB 9093), the Kenya Medical Research Institute Scientific Ethics Review Unit (SERU 3888), and the World Health Organization Ethical Review Committee (ERC 0003186). Before being included in the study, written informed signed consent was obtained from the participants. During the consenting process, the study was described and the consent form read in the participant's chosen language by the study staff. The consent form detailed the purpose and design of the study, descriptions of study benefits and risks, and a statement about voluntary participation and the freedom to drop out of the study at any time and without prejudice. Participants who were illiterate were asked to appose their thumbprint and a literate witness (known/selected by the participant and having no connection to the research team) was asked to sign. All participants were provided with a signed copy of the consent form after agreeing to participate in the study.

\section{Consent for publication}

Not applicable.

\section{Competing interests}

The authors declare that they have no competing interests.

\section{Author details}

${ }^{1}$ Centre for Global Health Research (CGHR), Kenya Medical Research Institute (KEMRI), Kisumu, Kenya. ${ }^{2}$ Johns Hopkins Center for Communication Programs, Baltimore, MD, USA. ${ }^{3}$ Johns Hopkins Bloomberg School of Public Health, Baltimore, MD, USA.

Received: 10 November 2020 Accepted: 11 March 2021 Published online: 23 March 2021

\section{References}

1. WHO. World malaria report 2020. Geneva: World Health Organization; 2020.

2. National Malaria Control Programme. Kenya National Bureau of Statistics, ICF International. Kenya malaria indicator survey 2015. Nairobi, 2016.

3. Malaria Consortium DNMP. President's Malaria Initiative. VectorLink integrated vector control strategy for malaria control-Kenya 2020-2024 Nairobi, 2019.

4. Kahindi SC, Muriu S, Derua YA, Wang X, Zhou G, Lee M-C, et al. Efficacy and persistence of long-lasting microbial larvicides against malaria vectors in western Kenya highlands. Parasit Vectors. 2018;11:438.

5. Derua YA, Kahindi SC, Mosha FW, Kweka EJ, Atieli HE, Wang X, et al. Microbial larvicides for mosquito control: impact of long lasting formulations of Bacillus thuringiensis var. israelensis and Bacillus sphaericus on non-target organisms in western Kenya highlands. Ecol Evol. 2018;8:7563-73.

6. Zhou G, Li JS, Ototo EN, Atieli HE, Githeko AK, Yan G. Evaluation of universal coverage of insecticide-treated nets in western Kenya: field surveys. Malar J. 2014;13:351.

7. Githinji S, Herbst S, Kistemann T, Noor AM. Mosquito nets in a rural area of Western Kenya: ownership, use and quality. Malar J. 2010;9:250.

8. Conteh L, Hanson K. Methods for studying private sector supply of public health products in developing countries: a conceptual framework and review. Soc Sci Med. 2003;57:1147-61.

9. Goodman C, Kachur SP, Abdulla S, Bloland P, Mills A. Concentration and drug prices in the retail market for malaria treatment in rural Tanzania. Health Econ. 2009;18:727-42.

10. Alba S, Hetzel MW, Goodman C, Dillip A, Liana J, Mshinda H, et al. Improvements in access to malaria treatment in Tanzania after switch to artemisinin combination therapy and the introduction of accredited drug dispensing outlets-a provider perspective. Malar J. 2010;9:164.

11. Alfonso YN, Lynch M, Mensah E, Piccinini D, Bishai D. Willingness-to-pay for long-lasting insecticide-treated bed nets: a discrete choice experiment with real payment in Ghana. Malar J. 2020;19:14.

12. Snow R, Peshu N, Forster D, Mwenesi H, Marsh K. The role of shops in the treatment and prevention of childhood malaria on the coast of Kenya. Trans R Soc Trop Med Hyg. 1992;86:237-9.

13. Amin AA, Snow RW. Brands, costs and registration status of antimalarial drugs in the Kenyan retail sector. Malar J. 2005;4:36.

14. Amin A, Snow R, Kokwaro G. The quality of sulphadoxine-pyrimethamine and amodiaquine products in the Kenyan retail sector. J Clin Pharm Ther. 2005;30:559-65.

15. Macintyre K, Keating J, Sosler S, Kibe L, Mbogo CM, Githeko AK, et al. Examining the determinants of mosquito-avoidance practices in two Kenyan cities. Malar J. 2002;1:14.

16. Ayaa DD, Waswa F. Role of indigenous knowledge systems in the conservation of the bio-physical environment among the Teso community in Busia County-Kenya. Afr J Environ Sci Technol. 2016;0:467-75.

17. Mutua FK, Randolph TF, Arimi SM, Kitala PM, Githigia SM, Willingham AL, et al. Palpable lingual cysts, a possible indicator of porcine cysticercosis, in Teso District, Western Kenya. J Swine Health Product. 2007;15:206-12.

18. Ochomo E, Bayoh NM, Kamau L, Atieli F, Vulule J, Ouma C, et al. Pyrethroid susceptibility of malaria vectors in four districts of western Kenya. Parasit Vectors. 2014;7:310.

19. Gachohi JM, Bett BK, Murilla G. Factors influencing the prevalence of trypanosomosis in Orma Boran (trypanotolerant) and Teso zebu (trypanosusceptible) cattle crosses in Teso District, western Kenya. Bull Anim Health Prod Afr. 2009:57:51676.

20. Ogoma SB, Moore SJ, Maia MF. A systematic review of mosquito coils and passive emanators: defining recommendations for spatial repellency testing methodologies. Parasit Vectors. 2012;5:287.

21. Avicor SW, Wajidi MF, Owusu EO. To coil or not to coil: application practices, perception and efficacy of mosquito coils in a malaria-endemic community in Ghana. Environ Sci Pollut Res. 2017;24:21138-45.

22. Msangi S, Mwang'onde BJ, Mahande AM, Kweka EJ. Field evaluation of the bio-efficacy of three pyrethroid based coils against wild populations of anthropophilic mosquitoes in northern Tanzania. J Glob Infect Dis. 2010;2:116

23. Lawrance CE, Croft AM. Do mosquito coils prevent malaria? A systematic review of trials. J Travel Med. 2004;11:92-6.

24. Sluydts V, Durnez L, Heng S, Gryseels C, Canier L, Kim S, et al. Efficacy of topical mosquito repellent (picaridin) plus long-lasting insecticidal nets 
versus long-lasting insecticidal nets alone for control of malaria: a cluster randomised controlled trial. Lancet Infect Dis. 2016;16:1169-77.

25. Wilson AL, Chen-Hussey V, Logan JG, Lindsay SW. Are topical insect repellents effective against malaria in endemic populations? A systematic review and meta-analysis. Malar J. 2014;13:446.

26. Dadzie S, Boakye D, Asoala V, Koram K, Kiszewski A, Appawu M. A community-wide study of malaria reduction: evaluating efficacy and user-acceptance of a low-cost repellent in northern Ghana. Am J Trop Med Hyg. 2013;88:309-14.

27. Alpern JD, Dunlop SJ, Dolan BJ, Stauffer WM, Boulware DR. Personal protection measures against mosquitoes, ticks, and other arthropods. Med Clin N Am. 2016;100:303-16.
28. Croft AM. Malaria: prevention in travellers (non-drug interventions). BMJ Clin Evid. 2014;2014:25399869.

29. Syafruddin D, Bangs MJ, Sidik D, Elyazar I, Asih PB, Chan K, et al. Impact of a spatial repellent on malaria incidence in two villages in Sumba, Indonesia. Am J Trop Med Hyg. 2014;91:1079-87.

\section{Publisher's note}

Springer Nature remains neutral with regard to jurisdictional claims in published maps and institutional affiliations.
Ready to submit your research? Choose BMC and benefit from:

- fast, convenient online submission

- thorough peer review by experienced researchers in your field

- rapid publication on acceptance

- support for research data, including large and complex data types

- gold Open Access which fosters wider collaboration and increased citations

- maximum visibility for your research: over $100 \mathrm{M}$ website views per year

At BMC, research is always in progress.

Learn more biomedcentral.com/submissions 